\title{
Student, Teacher, and Scientist Views of the Scientific Enterprise: An Epistemic Network Re-analysis
}

\author{
Erin E. Peters-Burton ${ }^{1} \cdot$ Zoubeida R. Dagher $^{2} \cdot$ Sibel Erduran $^{3}$
}

Received: 15 March 2021 / Accepted: 26 January 2022 / Published online: 10 February 2022

(c) The Author(s) 2022

\begin{abstract}
There is substantial research in science education about students', teachers', and scientists' views of nature of science (NOS). Many studies have used NOS frameworks that focus on particular ideas such as tentativeness of scientific knowledge and cultural embeddedness of science. In this paper, we investigate NOS from the perspective of the Family Resemblance Approach (FRA) which considers clusters of ideas about science in terms of categories that offer a comprehensive analytical lens to studying NOS views. The empirical study re-analyzes NOS views obtained from 7 and 8th grade students, science teachers, and scientists using the FRA lens. Statements from all three groups were obtained using a free-write questionnaire on nature of knowledge and nature of knowing. The statements were reclassified using the FRA framework. Epistemic network analysis (ENA) was applied to the statements produced by each group of participants, and the resulting network models were interpreted and compared. The results show that student and teacher network models possessed no central idea, and more tangible ideas about science were frequently connected. Scientist network models showed more connections across their statements which indicate a higher degree of agreement and coherence among a variety of ideas compared to student and teacher network models. The paper discusses the findings as well as the methodological contributions, and concludes with implications for future research.
\end{abstract}

Keywords Epistemic network analysis · Family Resemblance Approach · Nature of science $\cdot$ Science epistemology

Erin E. Peters-Burton

epeters1@gmu.edu

1 Donna R. and David E. Sterling Endowed Professor in Science Education, College of Education and Human Development, George Mason University, 4400 University Drive, MSN-4B3, Fairfax, VA 22030, USA

2 University of Delaware, Newark, USA

3 University of Oxford, Oxford, UK 


\section{Introduction}

Nature of science (NOS) is an area of research in science education that has emphasised the significance of understanding how science works (Lederman, 1992). Such understanding has been advocated as an educational goal, and many studies have been carried out to foster students' (Brunner \& Abd-El-Khalick, 2019; Lederman et al., 2002) and teachers' (Adibelli-Sahin \& Deniz, 2017; Milne, \& Taylor, 1995; Zion et al., 2002) understanding of NOS. Researchers have also investigated how professional scientists themselves understand NOS (Osborne et al., 2003; Schwartz \& Lederman, 2008; Tao, 2002; Wu \& Erduran, 2022). Studies on students' and teachers' views of science show a range of findings depending on the type and duration of NOS intervention (Cofré et al., 2019), the degree of explicit versus implicit NOS instruction (Adibelli-Sahin, \& Deniz, 2017), and the NOS framework used (Cheung, 2020).

There are several reasons for fostering NOS understanding in school science. First, a good understanding of NOS is a requisite component of becoming scientifically literate (Brunner \& Abd-El-Khalick, 2019; Lederman et al., 2002). Second, science teaching invariably presents views about NOS whether intended or not. Teachers' own views of NOS impact what science they teach and how they teach it (Akerson et al., 2019; Nouri \& McComas, 2021). This in turn impacts what students learn in science, what they learn about science, and how they engage in science.

Studies on scientists' views of NOS have shown a diverse range of ideas. In an investigation of scientists' views of NOS, Schwartz and Lederman (2008) affirmed that scientists' NOS views are complex and multi-faceted. Similar observations have been noted by other researchers regarding scientists' views about the nature of scientific knowledge, scientific investigations, and social practices of scientists (Wong \& Hodson, 2009). When using an epistemic network analysis on responses of in-service and pre-service teachers to extend interpretation of a well-known instrument, VNOS-B, Peters-Burton et al. (2019) found a lack of hierarchy among NOS ideas of participants and an intermingling of NOS tenets in a single cluster of ideas.

\section{NOS Views Within Different Groups}

Despite a wealth of research on NOS views, there is limited understanding of how different cohorts such as students, teachers, and scientists might approach a given set of questions and activities related to NOS. Considering that these groups interact within communities that have their own norms and practices, it is safe to assume that they are likely to approach a given task differently (Knorr-Cetina, 1999). Such an assumption raises a number of questions: How do these different groups approach the same NOS-related task? Do their views converge on a few big ideas or are they dispersed across less identifiable ones? Do these different groups connect the same ideas differently? What insights would a comparative 
analysis of student, teacher, and scientist reveal about their NOS views? Such questions suggest the need for a methodological approach that can trace the similarities and the differences between the different cohorts.

In an earlier study, Peters-Burton \& Baynard (2013) conducted a comparison of network models of scientists, middle school science teachers, and middle school students using the consensus framework of NOS (Lederman et al., 2002) for the data analysis. As interpreted by the consensus view of NOS, student networks produced ideas about subjectivity and objectivity, tentativeness, and creativity. The teacher networks only addressed subjectivity and objectivity, and tentativeness, and the scientist networks depicted scientific methods and the tentative and theory laden aspects of science.

But what happens if data obtained from these cohorts are re-analyzed using an alternative theoretical framework? What does applying a different theoretical lens reveal about distinctions between different cohorts' views? Building on calls for "more empirical research ... to evaluate the different theoretical approaches that have been proposed, such as the family resemblance approach" (Cofré et al., 2019, p. 243), the authors undertook an empirical investigation to explore how students, teachers, and scientists view the scientific enterprise not for the aim of evaluating a new framework, but for the purpose of exploring its affordances for revealing new patterns in the data. Using a different theoretical lens to analyze data sets obtained from the three cohorts allows for the possibility of identifying alternative views about science that supplement or expand the originally reported patterns. While differences are to be expected, determining what new patterns will be revealed cannot be pre-established, thus necessitating the re-analysis described in this study.

The authors chose the Family Resemblance Approach (FRA) to NOS (Erduran \& Dagher, 2014) as a new theoretical lens to re-analyze previously obtained data from students, teachers, and scientists (Peters-Burton \& Baynard, 2013). The FRA framework differs from the consensus framework of NOS (Lederman et al., 2002) in terms of its content and scope, with its different orientations to the cognitive-epistemic aspects of science and its inclusion of the social, institutional, and political dimensions (see the next section). New ways to conceptualize NOS are emerging (Leung, 2020; Romero-Maltrana \& Duarte, 2020). The authors hypothesized that applying the FRA interpretive lens in this context is likely to provide additional methodological and conceptual insights to the existing literature.

The empirical study reported in this paper addresses the following two research questions:

1. What features characterize students', teachers', and scientists' epistemic network models when their views are interpreted by the FRA framework?, and

2. What similarities and differences emerge across students', teachers', and scientists' epistemic network models when interpreted by the FRA framework?

Hence, we next turn to a description of the FRA to provide the theoretical background to this recent NOS framework. 


\section{Family Resemblance Approach to Nature of Science}

The Family Resemblance Approach (FRA) to nature of science is a framework, originally developed by philosophers of science Irzik and Nola (2014), called attention to the importance of including the cognitive-epistemic and social-institutional dimensions of science in science education. The categories in the cognitive-epistemic dimension are scientific activities, aims and values, methods and methodological rules, and knowledge. The categories in the social-institutional domain are professional activities, social certification and dissemination, social values, and scientific ethos.

Erduran and Dagher (2014) significantly extended Irzik and Nola's (2014) FRA account by linking the proposed NOS content to science education research and adding three new categories to the original FRA: political power structures, financial systems, and social organizations and interactions. These additions primarily pertain to the social-institutional aspects of science. They justified these categories by noting their growing significance in contemporary accounts of scientific practice, and their relevance to science education. The added categories provide further nuance to the social and institutional dimensions of science.

Each FRA category serves as referent for pertinent NOS content that cannot be captured in one statement. Rather each category consists of several constructs that are generally recognized as important components of scientific work. The following descriptions offer a brief introduction to the FRA categories:

1. Aims and values: The scientific enterprise is underpinned by adherence to a set of values that guide scientific practices.

2. Practices: The scientific enterprise encompasses a wide range of cognitive, epistemic, and discursive practices.

3. Methods and methodological rules: Scientists engage in disciplined inquiry by utilizing a variety of observational, investigative, and analytical methods to generate reliable evidence.

4. Knowledge: Theories, laws, and models are interrelated products of the scientific enterprise that generate and/or validate scientific knowledge and provide logical and consistent explanations to develop scientific understanding.

5. Professional activities: Scientists engage in a number of professional activities to enable them to communicate their research, including conference attendance and presentation, writing manuscripts for peer-reviewed journals, reviewing papers, developing grant proposals, and securing funding.

6. Ethos: Scientists are expected to abide by a set of norms both within their own work and during their interactions with colleagues and scientists from other institutions.

7. Social certification and dissemination: By presenting their work at conferences and writing manuscripts for peer-reviewed journals, scientists' work is reviewed and critically evaluated by their peers.

8. Social values: The scientific enterprise embodies various social values including social utility, respecting the environment, freedom, decentralizing power, honesty, addressing human needs, and equality of intellectual authority. 
9. Social organizations and interactions: Science is socially organized in various institutions including universities and research centers.

10. Political power structures: The scientific enterprise operates within a social and political environment that imposes its own values and interests.

11. Financial systems: The scientific enterprise is mediated by economic factors that influence research priorities, and who benefits from the produced knowledge.

Each category refers to clusters of ideas that cannot be boiled down to one single characteristic of science. The category of scientific practices, for example, refers to a detailed set of cognitive and discursive practices (such as classifying, modelling, and explaining to name a few) and how they relate to one another in discipline-based contexts. These components are detailed by Erduran and Dagher (2014) and supplemented with rich descriptions and heuristics for teaching-learning and research purposes. Several FRA categories are accompanied by visual images that serve as reminders for teachers and researchers to approach NOS content holistically. The FRA wheel (see Fig. 1) provides an overview of target NOS content by representing the NOS categories as interrelated not as independent entities as represented by the dotted lines. The representation is intended to help with the key types of categorisations that are included in the FRA framework proposed by Erduran and Dagher (2014). From a visual standpoint, having three concentric circles facilitates to differentiate the cognitive-epistemic, social, and institutional aspects of NOS represented in FRA. Such clustering is merely an artifact of the demands of clear visual representation so that 11 categories are easier to process by an observer.

The FRA framework has garnered support within the science education community (e.g. Cheung, 2020; Couso \& Simmaro, 2020; Petersen et al., 2020). For example, FRA has been applied to studies that focused on textbook analysis (e.g. BouJaoude et al., 2017; McDonald, 2017; Park et al., 2020) as well as studies that have investigated elementary (e.g. Akgun \& Kaya, 2020) and university students' understanding of NOS (Akgun \& Kaya, 2020). A growing number of studies have explored the merits of using this NOS approach in supporting teacher professional development (Erduran et al., 2021), analyzing curriculum policy documents (Park et al., 2020) and textbooks (BouJaoude et al., 2017), and pushing the FRA's conceptual boundaries further. Findings from studies using this approach in science education have been documented in a recent review (Erduran et al., 2019). However, although there is now a growing body of work on FRA in science education research, the potential of FRA as a theoretical framework for informing methodological approaches has rarely been tapped into. In particular, there is limited understanding about how FRA could potentially be coupled with other analytical tools such as epistemic network analysis (Cheung, 2020) to address research problems. Hence, the purpose of the empirical study described in the next section is to contribute to understanding of what new perspectives a re-analysis of existing ENA models based on the FRA framework may expose about how different cohorts' understanding of NOS can be identified and differentiated. 


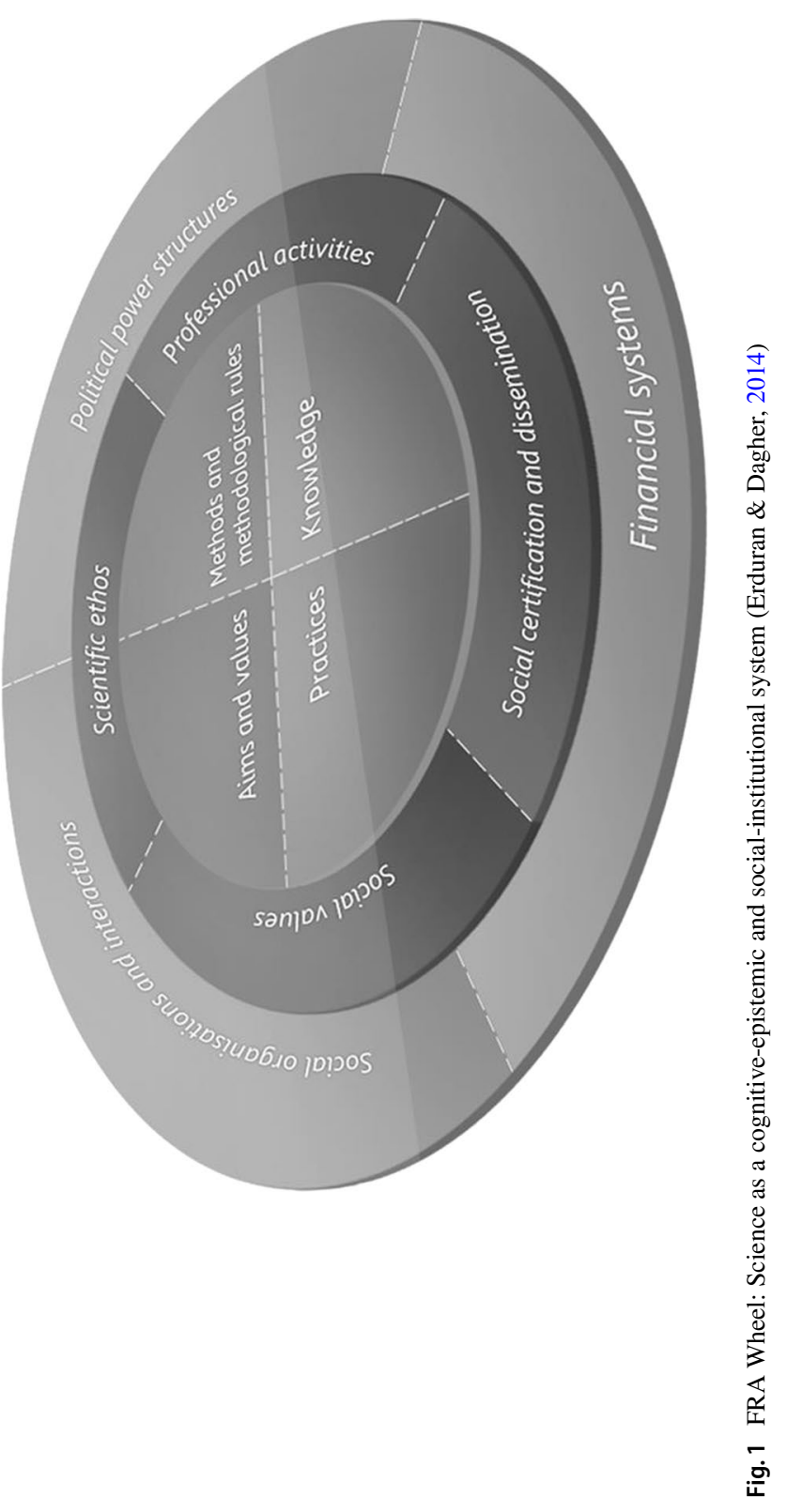




\section{Methodology}

The empirical study reported in this section applied an "epistemic network analysis" (ENA) to re-analyze data obtained from three groups of participants in a previous study. An epistemic network conceptualizes the most agreed-upon ideas of a group and how those ideas are connected to each other. An epistemic network model is a visualization that displays ideas of a group of people as nodes and the connectedness of those ideas as lines or edges connecting those nodes. The ENA approach used for this study was originally published by Peters-Burton and Baynard (2013). In the original study, the participants' statements were classified using the consensus view framework for nature of science prior to applying the ENA, and the same framework was used to interpret the generated network models. In this study, the participants' statements are reclassified using the FRA framework prior to using the ENA, and the FRA is used to interpret the findings. The questions posed to participants were based on a broad conceptual framework focused on nature of knowing and nature of knowledge (Hofer \& Pintrich, 2002). This broad conceptual framework was not aligned with any particular NOS perspective, thus making it possible to analyze the data from emergent NOS perspectives.

\section{Participants}

The participants from which the original data set was obtained consisted of a convenience sample consisting of 80 students aged 11 to 14 years old, 23 middle school teachers, and 10 scientists from a major research university (two geoscientists, two physicists, two chemists, and four biologists). The students were all from the same school, but the teachers came from different schools in a single state in the USA. The teachers were recruited during a professional development experience on watersheds that they were attending. The scientists were active researchers who were involved with both undergraduate and graduate students. Using a convenience sample was deemed acceptable because the purpose of this study is to re-analyze the data from a different NOS perspective, rather than develop broad generalizations concerning the three groups of participants. At the time of data collection, all students from two 7th and 8th grade classes participated in the study. The students who participated in this study are likely to be more sophisticated in their views of NOS than other 11 to 14 year olds because they took a full-year elective course on citizen science, featuring ideas about the nature of science (Peters-Burton, 2015). The teachers were teaching 7 th or 8 th grade science.

\section{Procedures}

The data that were re-analyzed in this study were originally obtained by asking each participant to independently answer four open-ended questions that were aligned to Hofer and Pintrich's (2002) conceptualization for epistemology. Hofer and Pintrich's framework for epistemology included two dimensions, the nature of knowledge and 
the nature of knowing. Each of these dimensions included two sub-dimension continuums that further described the dimension. For the nature of knowledge, the two sub-dimensions are the certainty of knowledge, which ranges from a more naïve idea of knowledge being absolute to a more sophisticated idea of knowledge being self-correcting, and the simplicity of knowledge, which ranges from a naïve view of knowledge as a collection of isolated facts to a more sophisticated view of knowledge being inter-rated facts. For the nature of knowing, the two sub-dimensions are the source of knowledge, ranging from a naïve view of knowledge coming from outside authority to a more sophisticated view of knowledge being constructed by experiences, and the justification of knowing, which ranges from a naïve view of knowing because of conformity to a group to a more sophisticated view of knowing as a rational act. The extremes of the sub-dimension continuum for each category in the dimension can be seen in Fig. 2. All participants completed four open-ended questions individually on their own time and were allowed to take as much time as they needed to answer the questions.

The two questions about the nature of knowledge were: (a) How are scientists sure the information they learn is "scientific"? (b) How do people know that things like a horoscope are NOT "scientific"? The two questions about the nature of knowing were: (a) How do you think scientists gather knowledge? (b) How do you think scientists know the knowledge they gather is as correct as possible?

Second, each group's answers to the four open-ended questions were qualitatively open coded for the statements that had meaning for NOS. For example, a participant statement that said "I love science" would not be coded, because it does not have meaning for NOS. However, if a participant statement said "science is made up of facts," it would be coded because this statement has meaning for NOS. There was only one utterance from a student in the data set that was not coded for NOS. Each statement that was an utterance of meaning about the scientific enterprise was captured and placed on an index card with a sequential number, so that each statement can be uniquely identified in the conversion to a unit matrix explained below.

Third, each participant was given the numbered statements on index cards to sort. The group statements were only given to participants from that group. For example,

Nature of knowledge

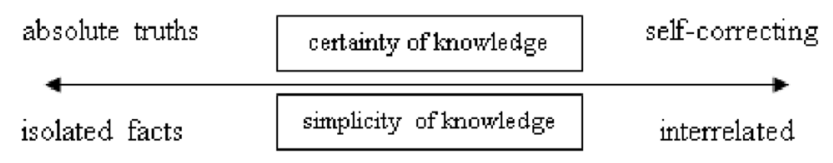

Nature of knowing

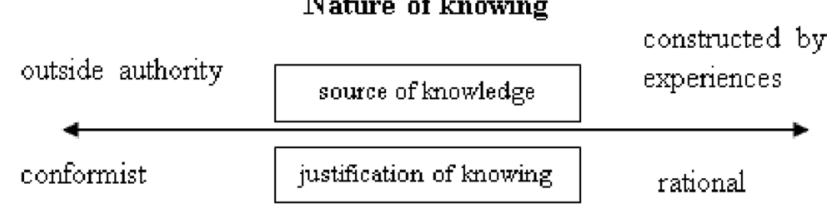

Fig. 2 Conceptualization for the open-ended questionnaire used in the study 
all students received the compiled statements collected only from the participating students. Participants were instructed to place the index cards in piles that made meaning to them. Participants were also instructed to leave out cards from the piles for three reasons: (a) they did not agree with the statement, (b) they could not make sense of the statement, or (c) they decided it did not represent ideas about NOS. Sorting the cards into piles indicated how the participants grouped the statements. Then, the identification numbers of the cards in each pile were recorded for each participant and these data were ready for an epistemic analysis.

\section{FRA as Analytical Framework}

In order to generate network models using the FRA framework categories illustrated in Fig. 1, which are further explained in the book Reconceptualizing the nature of science for science education: Scientific knowledge, practices and other family categories, the three authors in this study first had to re-analyze the participants' statements. Thus, each author independently examined each statement generated by the participants in the group and classified it into a corresponding FRA category. The process involved comparing the theoretical definitions of the analytical framework and the empirical statements generated by the participants, and how they might relate to each other (Strauss \& Corbin, 1998).

Initially, the authors had disagreement with the categorization of $20 \%$ of student statements, $38 \%$ of teacher statements, and $19 \%$ of scientist statements, mainly around the statements' fit into one or both categories of "Methods" or "Practices." The authors met to discuss these discrepancies and agreed that the "Practices" category referred to details of scientific practices (e.g. testing, classifying, modelling, predicting) compared to the larger approach typically ascribed to the "Methods" category. For example, take teacher statement \#1: "Scientists use the scientific method - testing and proving a hypothesis." This statement can be taken as focused on method, if one emphasizes the first part, or on the idea of "proving" or"disproving" a hypothesis (possibly fitting under practice). The team decided this statement fits more under methods since the details are subservient to the idea of a strict and notion of scientific method. In comparison, teacher statement \#6: "Scientific knowledge comes from constant experimentation and re-experimentation" was classified under the practices category, because it specifies a component activity that is grounded in obtaining reliable data. This eventually led to achieving a $100 \%$ agreement on the categorizing participant statements relative to the FRA framework. The classification of student, teacher, and scientist statements into the FRA categories is presented in Appendices 1, 2, and 3 respectively.

\section{Epistemic Network Analysis}

Epistemic network analysis (ENA; Hanneman \& Riddle, 2005) was used as an analytical approach to interpret the data (see https://www.epistemicnetwork.org/). ENA was derived from the more common social network analysis method (Scott, 1988). The output of the ENA is referred to as a network model. ENA is a conversion mixed method 
(Teddlie \& Tashakkori, 2009) where qualitative statements gathered from open-ended questions are grouped in piles to make meaning and quantified using frequency of pairings in the piles. The quantifications are displayed using dimensional analysis to show meaningful connections among the ideas in a 2-dimensional visualized network model.

After each group completed the index card sort described in the "Procedures" section, the card numbers that were grouped together were placed into a unit matrix for each individual. For example, if a participant grouped card 5, card 10, and card 17 together in a pile, a "1" was recorded in the unit matrix for that person in row 5 and column 10 and column 17; row 10 and column 5 and column 17; and row 17 and column 5 and column 10. The resulting individual matrix consisted of $1 \mathrm{~s}$ or $0 \mathrm{~s}$ in all cells of the matrix. The individual unit matrix cells were added across the group to develop the compiled group matrix. The three compiled group matrices were uploaded to the software UCINET to visualize the results for each group.

One limitation of this method is allowing participants to sort statements generated from all members of their group, thus exposing participants to ideas that were not their own. To account for this limitation, multidimensional scaling was performed, which only displays the most frequent relationships among the group, creating a network model that displays $75 \%$ of the most frequent connections. This is done by organizing the frequency of pairings into quartiles. The lowest quartile of statements is not displayed on the network model. Multidimensional scaling was chosen in the software to reconfigure each model so that the distance between each node is inversely proportional to the frequency of co-occurrence (Shaffer et al., 2009, 2016). By eliminating the statements that were not agreed upon by the group, we hope to represent the central or key ideas of the cultural epistemology of the group (Knorr-Cetina, 1999).

The visualizations or network models consist of nodes (statements from the participants) and edges (lines connecting statements from the participants). Network models produced for this study were interpreted visually by examining the centrality of nodes, clustering of nodes, density of edges, and distances between nodes. The nodes located centrally on a network model are the nodes representing statements that are most frequently connected to other nodes (statements) in the model. Nodes that are clustered on the network model represent ideas that the participants perceive as related to each other. Similarly, high density of edges (lines between nodes) and small distances between nodes in a network model indicate that the participants closely connect those statements. The length of the edge between nodes represents the frequency of connection between two nodes. The short edges between two nodes represent a high frequency of pairing those two nodes in the group and the long edges represent a low frequency of pairing those two nodes in the group. Multidimensional scaling uses the inverse of the frequency of pairings to represent the edge in a network model.

\section{Results and Findings}

The results are organized in two sections each of which corresponds to the study's research questions. First, we present features of the network models for the three groups of participants as interpreted through the FRA framework. Second, we compare student, teacher, and scientist network models. 


\section{Features that Characterize Students', Teachers', and Scientists' Epistemic Network Models}

Student Network Model with FRA Interpretation Six categories of the FRA framework were represented on the student network model: Practices, Knowledge, Methods, Professional Activities, Ethos, and Aims and Values. When analyzed by the FRA framework, all of the ideas represented on the student network model fit into FRA categories. As seen in Fig. 3, the FRA categories accounted for all of the idea nodes and for the most part had consistency with categories within clusters. However, each cluster represented more than one category from the FRA model.

The two categories Practices and Methods tended to be dominant in three of the four clusters. The ideas representing science practices intermingled with ideas about Methods, Knowledge, Aims and Values, and Ethos. These three clusters, comprising of science practices, knowledge, methods, and aims and values, correspond to all of the cognitive-epistemic aspects of the FRA which underscores their connection and coherence. Students drew ideas from the social aspects of the FRA and connected them, as illustrated in the bottom left cluster of Fig. 3. This indicates that students can clearly understand the professional activities of science as distinct from Practices, Knowledge, and Aims and Values. Similar to the other clusters, there is one idea about Methods mixed into the clusters.

Students' ideas aggregated into the fourth cluster on the network model that exclusively represented professional activities, a social-institutional category belonging to the second ring of the FRA wheel. Of the categories in the second ring of the FRA wheel, Social Certification, Social Values, Professional Activities, and Scientific Ethos, only the latter two were represented in the student network model. Ideas about Professional Activities were grouped together, but ideas about Scientific Ethos were incorporated into ideas about science practices. This may be because Professional Activities are observable and distinct as compared to Science Ethos which tend to be more implicit and embedded; thus, 11 to 14 year olds could more easily recognize ideas about professional activities to sort them together.

Overall, the four cognitive-epistemic aspects of FRA were well-represented on the student network model, making up 17 of the 21 nodes. The social-institutional aspects represented on the second ring on the FRA wheel were present in only four of the 21 student statements, indicating that students paid less attention to social activities of science. However, students' references to professional activities were prevalent enough to aggregate in a cluster, indicating that they recognized them as distinct, although scant. Students did not make any statements that addressed the Financial and Political Aspects category of the FRA. In contrast, the majority of statements made by the students about scientific methods and scientific practices were paired frequently enough to be present on the network model. This would indicate that students appear to express a higher level of awareness of tangible methods and practices of scientists, some awareness about professional activities, but are less aware of the underpinnings of aims and values of science and of broader social, political, financial, and institutional aspects of science. 


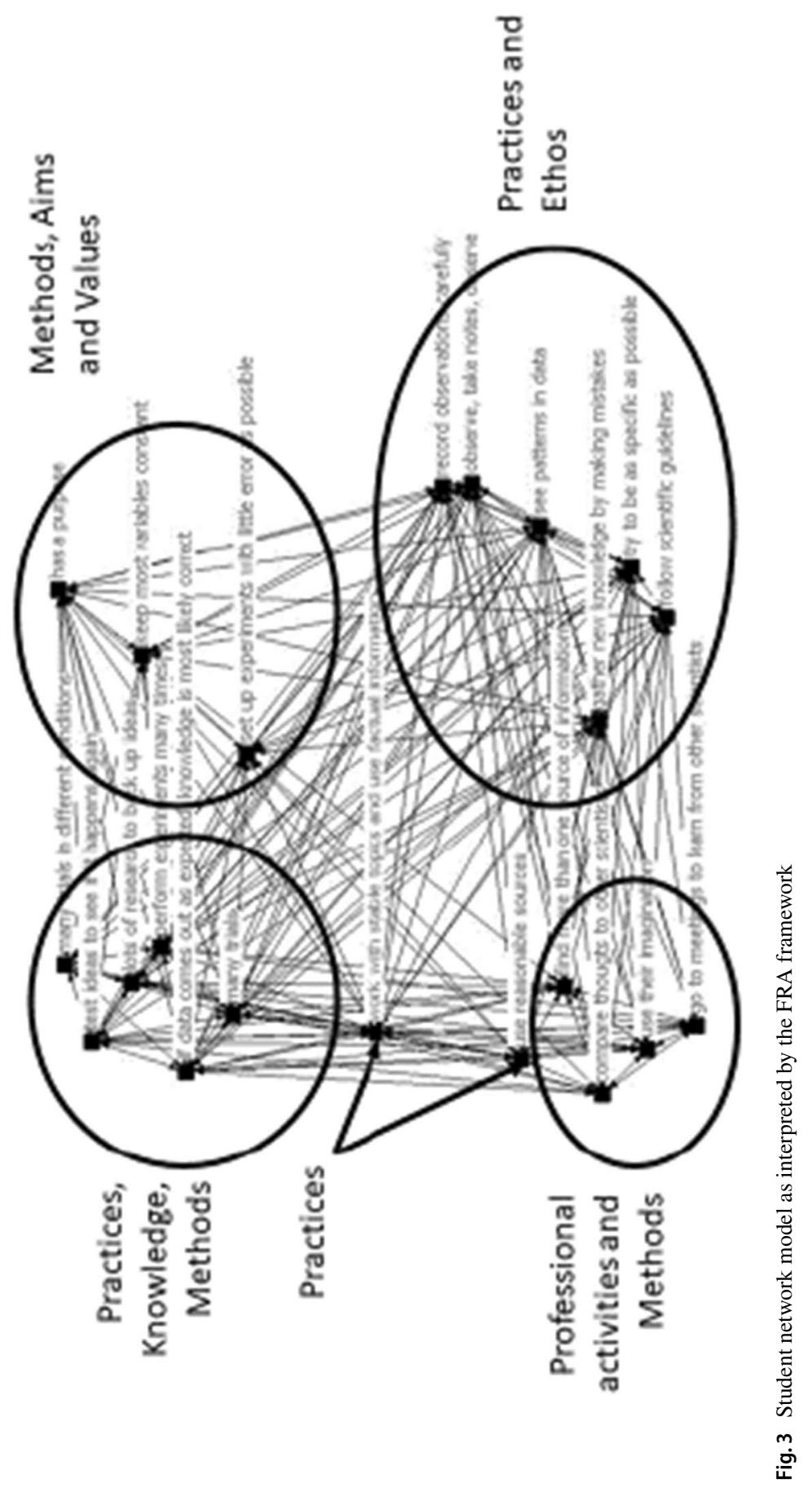


Teacher Network Model with FRA Interpretation Teachers' statements were mostly associated with four FRA categories: Methods, Practices, and Aims and Values (see Appendix 2). As discussed in Peters-Burton and Baynard's 2013 article, the members of the teacher group excluded so many cards from their individual pile categories that 15 of the statements did not appear on the map. They did so because either they did not agree with the statement or they did not understand it.

When analyzed through the lens of the FRA, the teacher statements that were retained on the network model mainly fell into the cognitive-epistemic realm. Four categories from the FRA framework were represented on the teacher network model: Practices, Methods, Knowledge, and Aims and Values. All of the categories from the social-institutional dimensions of the FRA were missing from the teacher network model (see Fig. 4). This may reflect teachers' primary focus on school science goals which tend to be inquiry-oriented as noted in the science teaching standards for the state in which the teachers taught.

As mentioned earlier, the teachers' statements were mostly associated with Methods, Practices, and Aims and Values (see Appendix 2). This focus seems partly consistent with the focus of the standards on scientific practices. Like the students, the more tangible ideas about science, such as methods and practices in science, were paired frequently enough to appear in the network model. Again, similar to the student network model, teachers described some of the aims and values in science through the network model but left out many of the more abstract ideas about this category such as seeking neutrality and avoiding bias, recognizing opposite ideas and responding to objections, taking opposition to own ideas seriously, and considering and respecting human needs.

Scientist Network Model with FRA Interpretation Eight categories from the FRA framework were represented on the scientist network model: Methods, Practices, Knowledge, Aims and Values, Social Certification, Ethos, and Professional Activities. Only two statements, both from Practices, were not agreed upon by the scientists enough to be present on the network model. All of the statements were from the cognitive-epistemic and the middle ring of the social-institutional categories of the FRA wheel, and like the student and teacher network models, none of the statements aligned with those aspects of the social-institutional categories that were located at the outer ring of the FRA wheel. The categorization of scientist statements by the FRA interpretation is presented in Appendix 3.

As shown in Fig. 5, the network model's radially oriented spread had four central statements from the cognitive-epistemic inner ring of the FRA wheel with the exception of the Knowledge category. Of the three FRA categories from the inner circle, Aims and Values were more frequently represented than ideas about Methods and Practices. Of the cognitive-epistemic aspects, all scientist ideas about Methods and Aims and Values were connected enough to be represented on the network model.

Like the inner circle of the scientist network model, the second concentric circle of statements represented ideas about aims and values and science practices. 


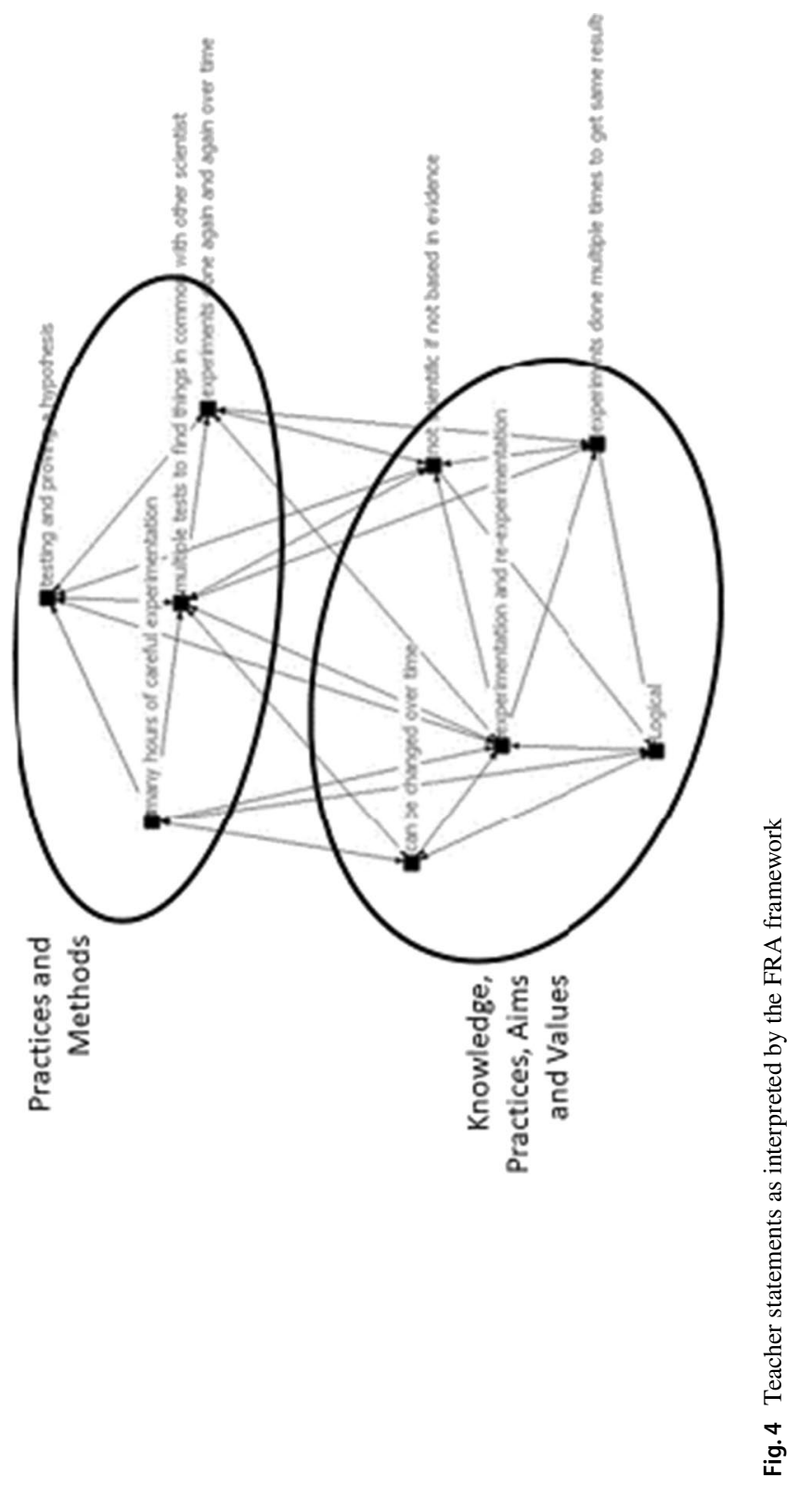




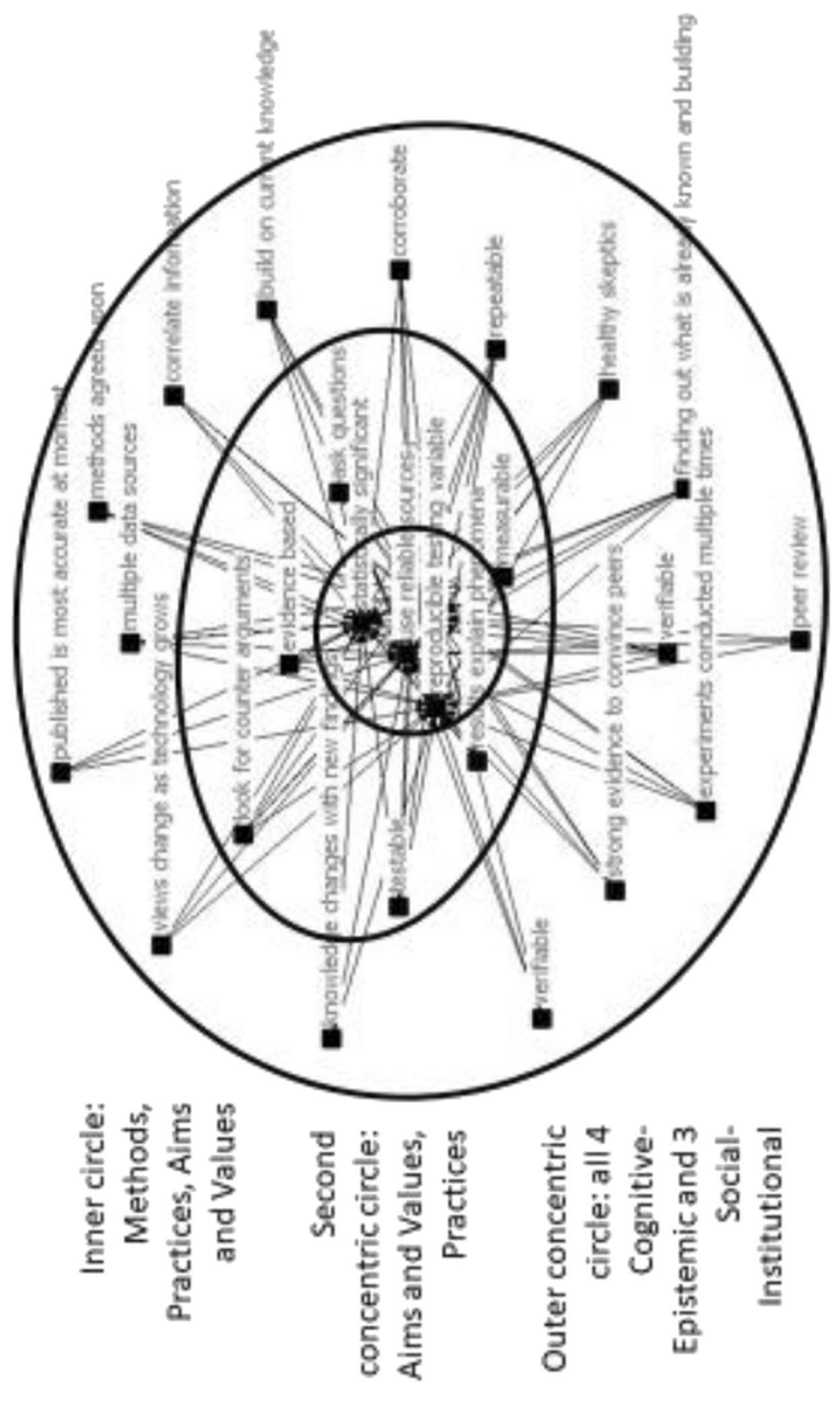

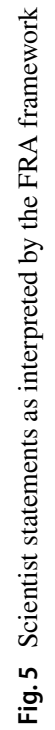


Because scientists deal with Aims and Values, Methods, and Practices directly with their work, they likely generated statements that reflect these types of tangible activities in response to the open-ended questions. The outer circle of statements in the scientist network model included a variety of statements, both from the cognitiveepistemic and social-institutional rings of the FRA model. Again, Aims and Values as well as science practices were mingled within other statements from the socialinstitutional aspects of the FRA.

\section{Similarities and Differences Across Students', Teachers', and Scientists' Epistemic Network Models}

To answer our second research question, we conducted a comparative analysis of the percentage of statements that were retained by each cohort on their respective networks. Figure 6 depicts the percentage of statements retained by each cohort on their network model under the cognitive-epistemic, social-institutional, and all categories of the FRA framework.

The highest number of statements in the cognitive-epistemic dimension was retained by scientists (90\%) followed by students $(66.7 \%)$ followed by teachers $(41 \%)$. In contrast, the highest number of statements in the social-institutional aspects of the FRA was retained by students $(75 \%)$, followed by scientists $(50 \%)$. None of the two statements generated by teachers in this dimension made it to their network model. When combining both dimensions of the FRA (all categories), the scientists' group retained most statements (81\%), followed by students $(68 \%)$ and teachers $(38 \%)$. It is worth noting that the students' statements in the social-institutional dimension of the FRA were related to Professional Activities and Ethos. Whereas the scientists' statements relative to this dimension addressed the three categories of Professional Activities, Ethos, and Social Certification, none of the groups generated statements that aligned with Social Values or any of the three outermost categories on the FRA wheel, namely, Social Organizations and Interactions, Political Power Structures, and Financial Systems.

The FRA framework includes a subordinate set of features under the category of Aims and Values. A secondary analysis of the statements that were classified under the Aims and Values category led to additional insights. While there is a total of 12 aspects of Aims and Values identified by Erduran and Dagher (2014), the participants' retained statements were distributed among only half of these subcategories as shown in Table 1. The subcategories were those described for Aims and Values in Erduran and Dagher (2014).

There is a notable difference in the number and distribution of statements across the three groups. Most evident is the scientists' apparent emphasis on "basing claims on sufficient and plausible data," and the fact that the scientists' network map shows 


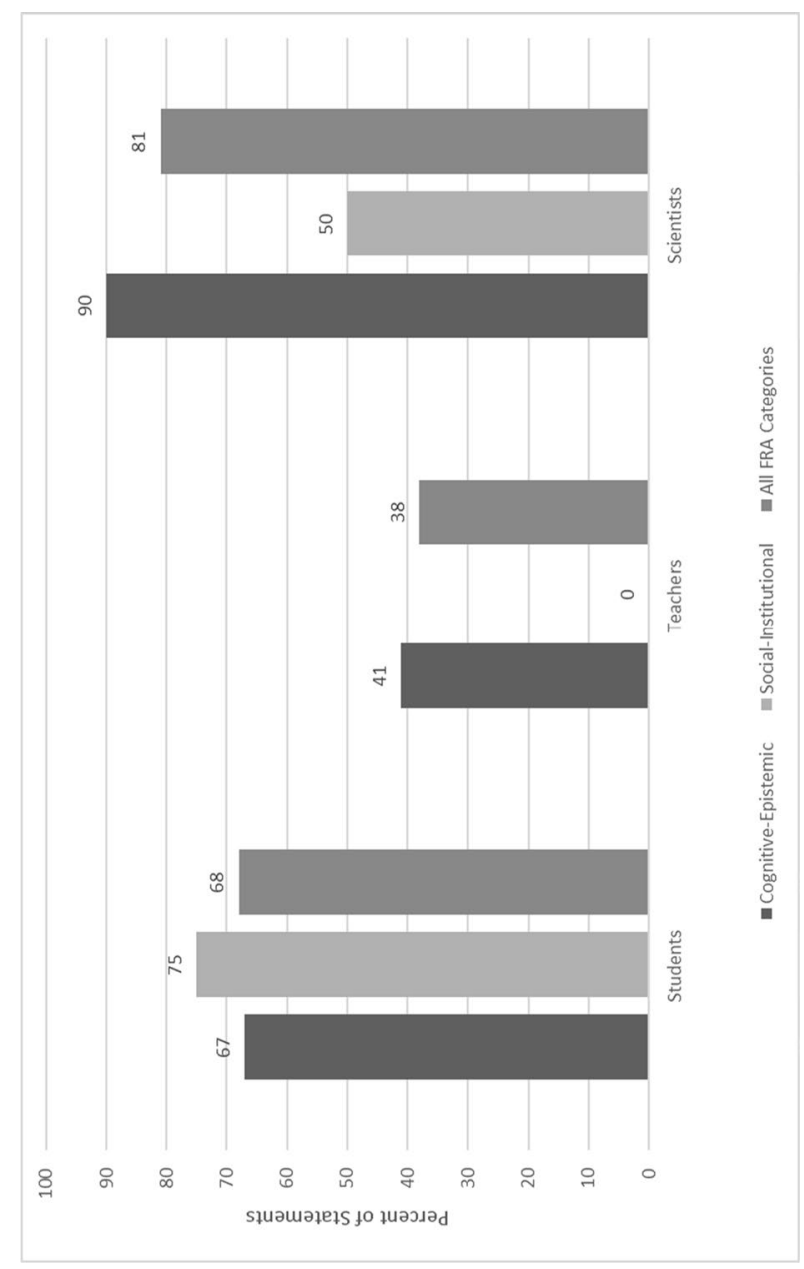

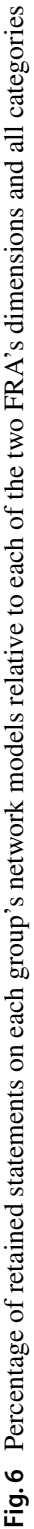


Table 1 Number of statements retained on network models classified under the subcategories of Aims and Values

\begin{tabular}{lllc}
\hline $\begin{array}{l}\text { Statements retained on network models under the } \\
\text { Aims and Values category: }\end{array}$ & Students, $N=80$ & Teachers, $N=23$ & $\begin{array}{l}\text { Scien- } \\
\text { tists, } \\
N=10\end{array}$ \\
\hline Searching for new explanations & 1 & 0 & 1 \\
Ensuring that explanations are accurate & 0 & 0 & 1 \\
Basing claims on sufficient and plausible data & 1 & 1 & 4 \\
Giving reasons to justify claims & 0 & 1 & 0 \\
Taking opposition to own ideas seriously & 0 & 0 & 1 \\
Changing own ideas in light of evidence & 0 & 1 & 0 \\
Total & 2 & 3 & 7 \\
\hline
\end{tabular}

retention of seven ideas compared to two by students, and three by teachers, may point to the scientists heightened awareness of these values in guiding their work. Given the relatively small number of participants and the confines of the existing data set (e.g. inability to seek additional information from the participants), we suggest that exploring these differences in future studies offers a promising direction for capitalizing on the breadth and depth of the FRA to uncover patterns within and across different groups of participants.

The FRA categories on the network models did not cluster around discrete boundaries. Rather than seeing this as a limitation, we see it as a strength because it signals more interconnectedness among the participants' statements relative to NOS features captured in the FRA categories. This is consistent with the theoretical account of FRA in Erduran and Dagher (2014) which stipulates that the categories are holistic and interrelated. It is for this reason that the categories in the FRA wheel (Fig. 1) are conceptualized in an interactive state, mutually influencing each other as symbolized by the dotted lines within the visual representation.

Patterns depicted in the student network models were similar to those found in teacher network models possibly because both groups tend to be more attentive to tangible methods and practices of scientists, but less concerned about the relatively more elusive aims and values of science and the broader social-institutional categories. The network models from the scientist group had most statements correlate and most represented the FRA framework, echoing many of the same categories. What made the scientists' network model stand out is the evenly distributed connections around the categories, showing that, at least among these groups of participants, the scientists' views were most cohesive among the selected FRA categories even though they were not the most exhaustive (statements aligned with 7 out of the 11 FRA categories). 


\section{Discussion and Implications}

Using the ENA methodology to analyze NOS statements generated by three different groups of participants enabled the identification of ideas about science that most group members found relevant. The ENA allowed the identification of idea clusters that were strikingly different across the three groups of participants, even when the questions that were asked were identical. The differences in the network models are reflective of differences in the range and scope of ideas expressed by each group, with the scientists providing the most agreement within their cohort compared to students and teachers (Fig. 6). While differences across participant groups in terms of the range and degree of agreement of ideas are to be expected due to their background knowledge and experiences, this analysis identifies the specific nature of these differences in terms of a fairly broad set of ideas ranging from the epistemic to the institutional aspects of science.

While it is tempting to attribute the students' more robust network models (compared to those of the teachers) to their year-long engagement with a citizen science course that had embedded NOS elements, we prefer to offer this possibility as a question for future research. In other words, the differences in the students', teachers', and scientists' network models can be attributed to a number of factors. However, identifying these factors is beyond the scope of the data re-analyzed in this study. Future studies might want to investigate differences between students, teachers, and scientists using larger and more randomized samples to determine what patterns emerge.

\section{Application of the FRA Framework}

The FRA categories made it possible to accommodate a broad range of diverse set of NOS statements in a coherent manner. The FRA framework is flexible and encompasses levels of organization allowed for participant statements to be allocated to one of 11 categories that relate to the cognitive, epistemic, and social and institutional aspects of NOS. For example, FRA has a very explicit reference to the social certification activities in science which relate to the "social context" references in other NOS frameworks. If FRA is used as an analytical framework, then it is more likely that this nuance will be picked up in an explicit manner.

The ENA enabled a fine-grained analysis of the composition of the resulting clusters for each participant group. Further analysis of individual FRA categories, such as Aims and Values, revealed additional details that would have otherwise gone unnoticed. For example, the student and teacher groups had markedly less statements about aims and values of science than the scientist group, providing evidence to inform the improvement of NOS education at the school level. 
Hence, the combination of FRA as a guiding theoretical framework and ENA as an analytical tool enabled us to observe fairly nuanced distinctions between the participants. There may be several implications of such an approach for research on NOS as well as the practical aspects of NOS teaching and learning. In terms of research, the paper provides details of qualitative data analysis based on FRA and ENA previously not synthesised together for such purpose, and thus offers a new perspective for future researchers on how to investigate different NOS views through a novel methodological approach. In terms of teaching practice, the study raises questions about how students' ideas may go unnoticed in the teaching environment when teachers may not share the same extent of specification about different aspects of NOS. Future teacher education interventions can capitalize on raising teachers' awareness about different FRA categories and how to recognise them in student contributions in the classroom.

The card sort process was effective in exposing the participants to other people's ideas in the group but presented some challenges as well. The more diverse the group, the more influence the ideas may have on participants during the second phase of the card sort. This may in part explain some of the differences noted across the participant groups, especially in relation to the teachers' network model, because the teachers work with written standards for NOS, and the other groups have implicit understandings of NOS. Future research may consider ways to address this limitation in relation to participant selection and administering the card sort task such as having participants initially sort their own card statements before sorting group statements. It is worth noting that the classification of participant statements in this study (using the FRA), as was the case in the 2013 study (using the Consensus View), did not address the accuracy of the participant statements. This is due to the fact that such judgements could not be discerned except in few cases due to the way the brevity of the statements solicited by the card sort task. Researchers interested in exploring the accuracy of participants' views may need to consider a different approach that lends itself to eliciting elaborate responses.

Considering that a convenience sample was used, it is not possible to draw definitive or generalizable conclusions about the identified variation between the different groups, especially in light of the students' exposure to NOS through the citizen science courses. However, the findings of this study affirm the usefulness of the ENA methodology for uncovering emerging patterns in data. Furthermore, applying the FRA analytical lens revealed where the student, teacher, and scientist statements stood in relation to a wider range of NOS ideas than has been previously explored (Peters-Burton \& Baynard, 2013). In the 2013 study, the authors were able to categorize clusters of student ideas into experimentation, building knowledge in science, and scientific guidelines. Although these ideas fit generally into NOS aspects of subjectivity and 
objectivity, tentativeness, and creativity, the clusters of ideas more precisely fit into the categories of the FRA.

In the 2013 study, the teacher networks addressed NOS aspects of subjectivity and objectivity, and tentativeness by connecting ideas about experimentation into one cluster. The re-analysis with the FRA was able to distinguish two clusters of teacher ideas (Practices and Methods, Knowledge, Practices, and Aims and Values). The scientist networks as interpreted in 2013 described aspects of science as theory laden, tentative, and scientific methods; however, many of the statements in the rings of the scientist statements loosely fit into those categories. By using the FRA, personal and social categories were not only identified among the statements, but they were distinct on the network model. The ENA revealed that scientists viewed social-institutional categories as different from cognitive-epistemic categories without any knowledge of the FRA framework.

\section{Recommendations for Future Research}

The insights gained from this re-analysis of student, teacher, and scientist data suggest that future descriptive and intervention studies can benefit from a pairing of the ENA and FRA to identify variation in the range and frequency of ideas across groups and identifying degrees of agreement or the lack thereof. These groups can be students at different grade levels (e.g. elementary, middle, high school, college) and in-service and pre-service teachers. For example, examining progression of teachers' network models across pre- and in-service teachers could potentially prove useful in identifying strategies for supporting teachers' learning. The pairing of the ENA and FRA can be also used to investigate scientists' and philosophers' views of science, thus providing alternative methodological tools to those that have been traditionally used to explore expert opinion (Osborne et al., 2003; Wong \& Hodson, 2009).

Future research could investigate the questions pursued in this study with a random sample to avoid any potential bias within the student, teacher, and scientist groups. Furthermore, future research can include follow-up interviews to find out more about the participants' thought processes as they engaged in the card sort task. Doing so can reveal additional details about how the participants' personal epistemologies and experiences influenced their choices. Finally, conducting in-depth interviews can help explain the factors that mediate or influence participant views. 


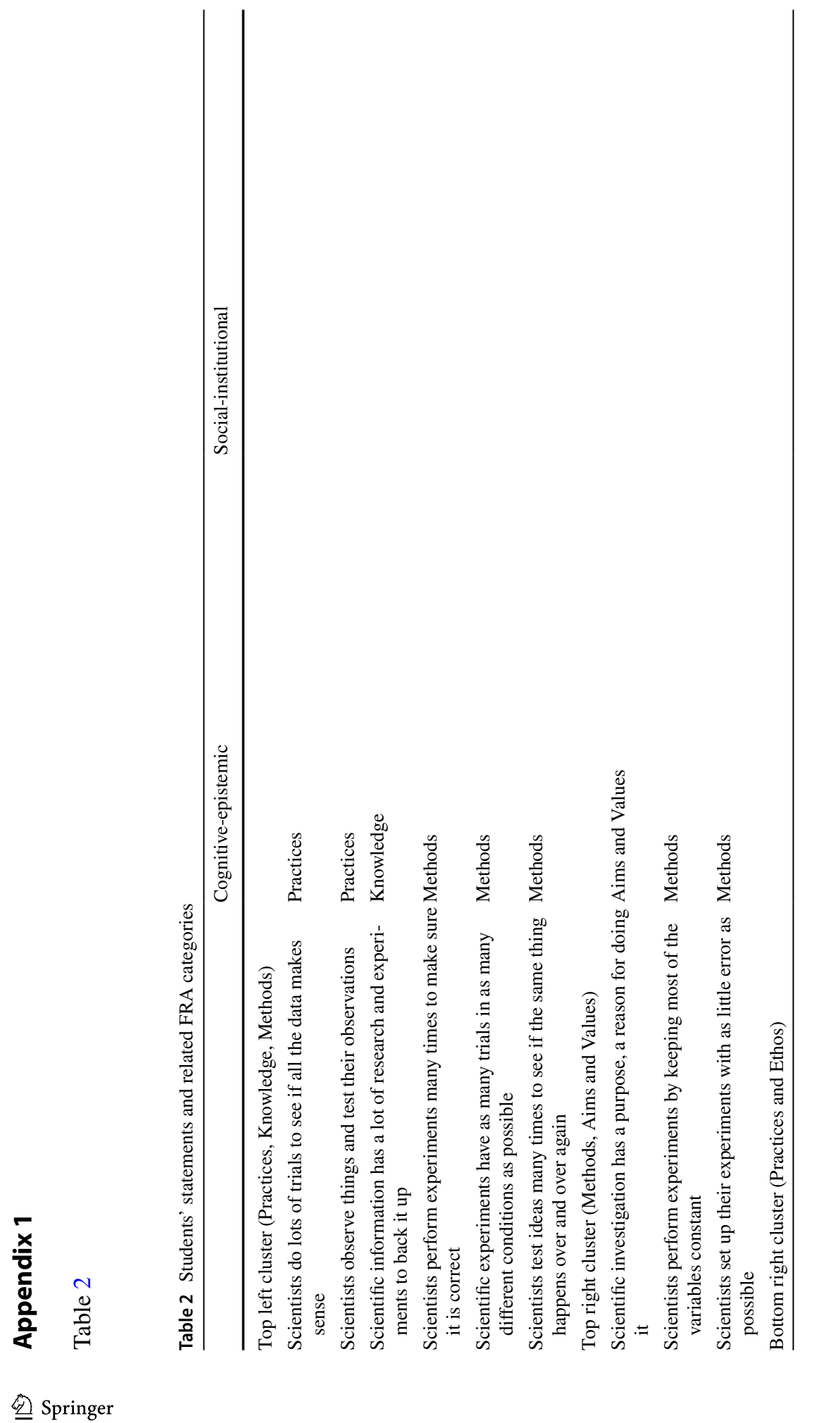




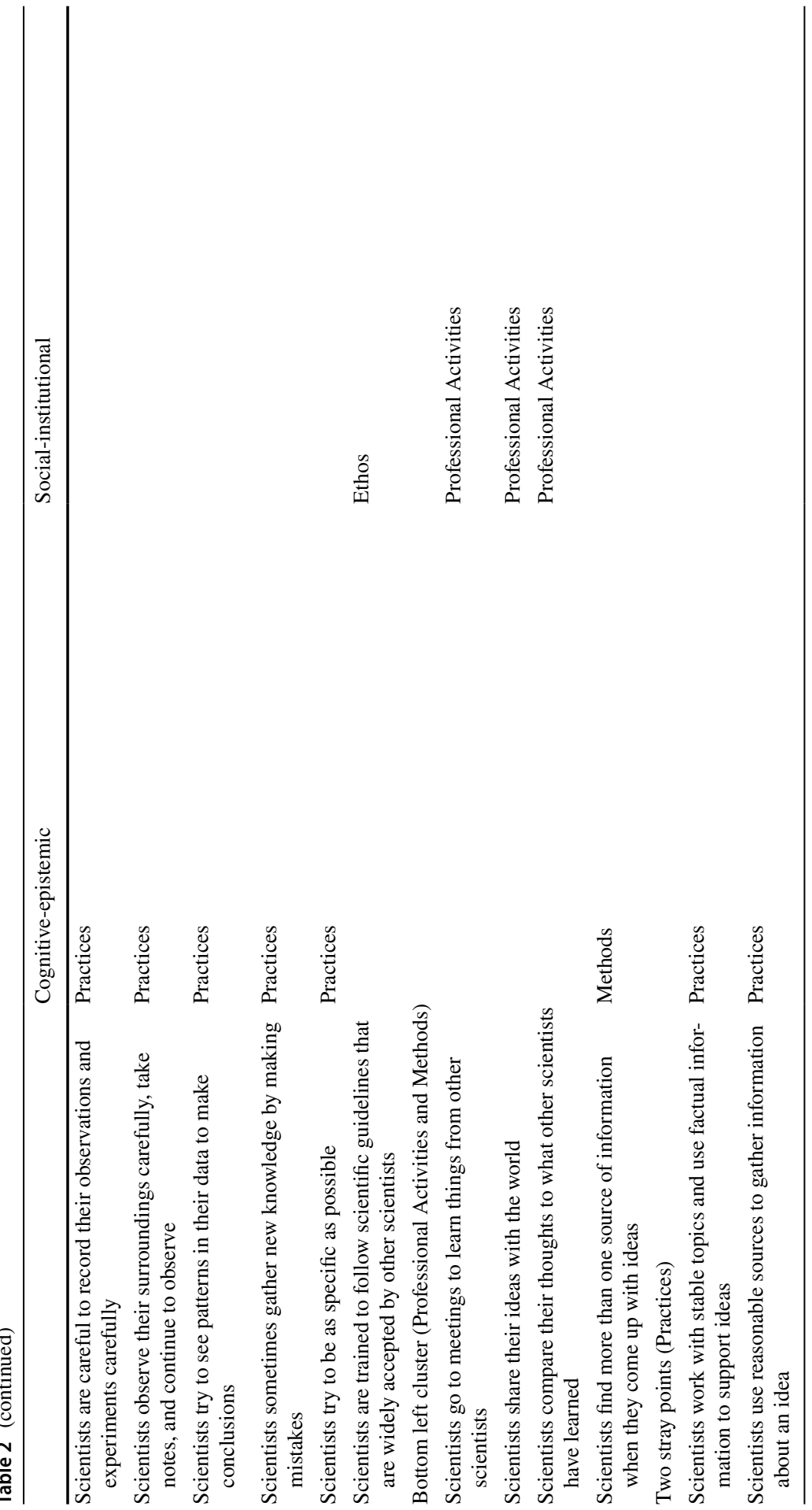




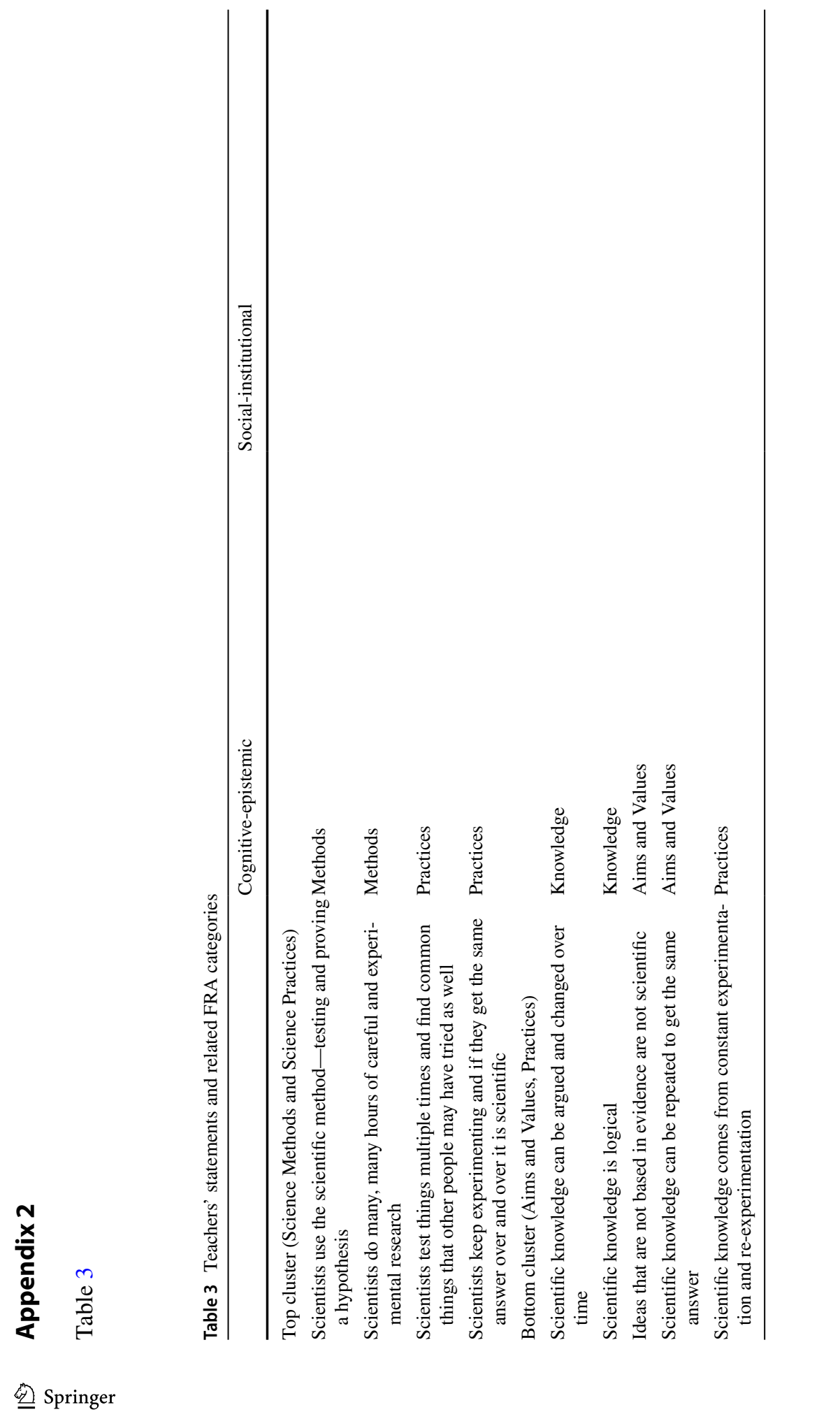




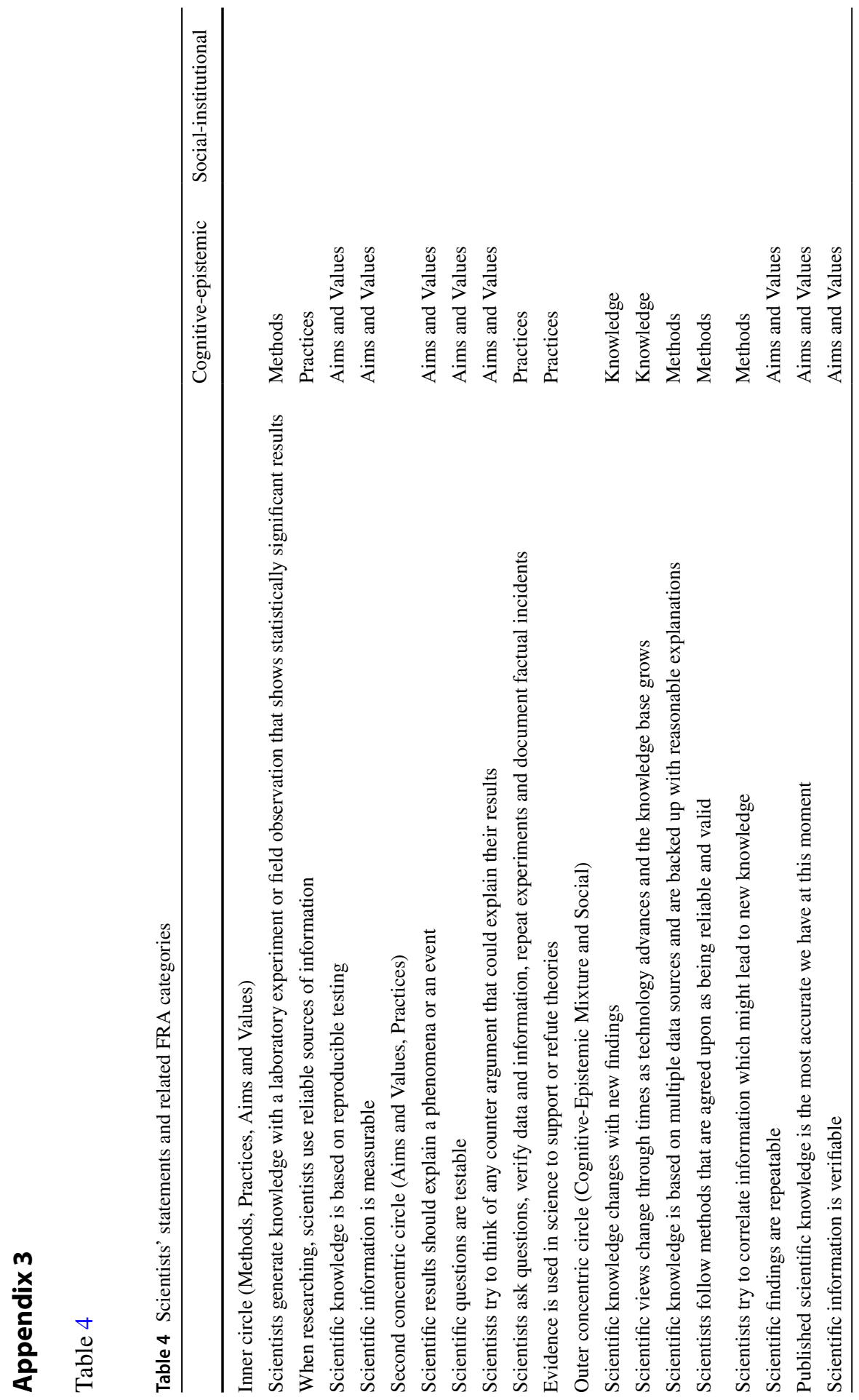




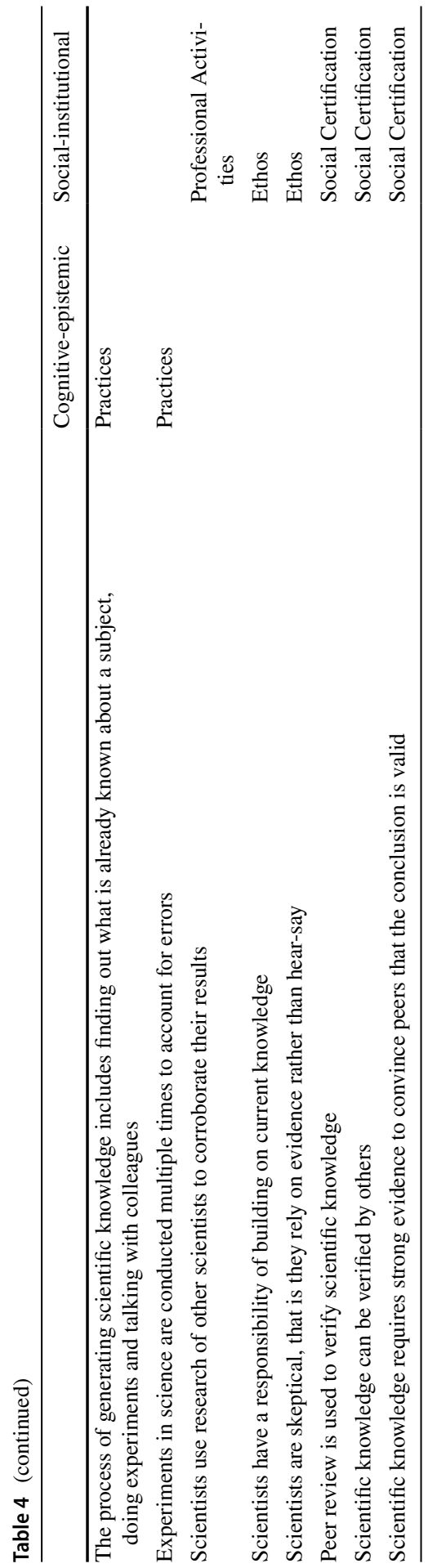


Acknowledgements There are no acknowledgements for this manuscript.

\section{Declarations}

Conflicts of interest The authors declare no competing interests.

Open Access This article is licensed under a Creative Commons Attribution 4.0 International License, which permits use, sharing, adaptation, distribution and reproduction in any medium or format, as long as you give appropriate credit to the original author(s) and the source, provide a link to the Creative Commons licence, and indicate if changes were made. The images or other third party material in this article are included in the article's Creative Commons licence, unless indicated otherwise in a credit line to the material. If material is not included in the article's Creative Commons licence and your intended use is not permitted by statutory regulation or exceeds the permitted use, you will need to obtain permission directly from the copyright holder. To view a copy of this licence, visit http://creativecommons.org/licen ses/by/4.0/.

\section{References}

Adibelli-Sahin, E., \& Deniz, H. (2017). Elementary teachers' perceptions about the effective features of explicit-reflective nature of science instruction. International Journal of Science Education, 39(6), 761-790. https://doi.org/10.1080/09500693.2017.1308035

Akerson, V., AvsarErumit, B., \& Elcan Kaynak, N. (2019). Teaching nature of science through children's literature: An early childhood preservice teacher study. International Journal of Science Education, 41(18), 2765-2787. https://doi.org/10.1080/09500693.2019.1698785

Akgun, S., \& Kaya, E. (2020). How do university students perceive the nature of science? Science \& Education, 29, 299-330. https://doi.org/10.1007/s11191-020-00105-x

BouJaoude, S., Dagher, Z. R., \& Refai, S. (2017). The portrayal of nature of science in Lebanese 9th grade science textbooks. In C. V. McDonald \& F. Abd-El-Khalick (Eds.), Representations of nature of science in school science textbooks: A global perspective (pp. 79-97). Routledge.

Brunner, J. L., \& Abd-El-Khalick, F. (2019). Improving nature of science instruction in elementary classes with modified science trade books and educative curriculum materials. Journal of Research in Science Teaching, 57(2), 154-183. https://doi.org/10.1002/tea.21588

Cheung, K. K. (2020). Exploring the inclusion of nature of science in biology curriculum and highstakes assessments in Hong Kong. Science \& Education, 2(3), 491-512. https://doi.org/10.1007/ s11191-020-00113-x

Cofré, H., Núñez, P., Santibáñez, D., Pavez, J., Valencia, M., \& Vergara, C. (2019). A critical review of students' and teachers' understanding of nature of science. Science \& Education, 28, 205-248. https://doi.org/10.1007/s11191-019-00051-3

Couso, D., \& Simmaro, C. (2020). STEM education through the epistemological lens: Unveiling the challenge of STEM transdisciplinarity. In C. C. Johnson, M. J. Mohr-Schroeder, T. J. Moore, \& L. D. English (Eds.), Handbook of research in STEM education (pp. 17-28). Routledge.

Erduran, S., \& Dagher, Z. (2014). Reconceptualizing the nature of science for science education: Scientific knowledge, practices and other family categories. Springer.

Erduran, S., Dagher, Z., \& McDonald, C. (2019). Contributions of the family resemblance approach to Nature of Science in science education: A review of emergent research and development. Science \& Education, 28(3), 311-328. https://doi.org/10.1007/s11191-019-00052-2

Erduran, S., Kaya, E., Cilekrenkli, A., Akgun, S., \& Aksoz, B. (2021). Perceptions of Nature of Science emerging in group discussions: A comparative account of pre-service teachers from Turkey and England. International Journal of Science and Mathematics Education, 19, 1375-1396. https://doi.org/10.1007/s10763-020-10110-9

Hanneman, R. A., \& Riddle, M. (2005). Introduction to social network methods. University of California.

Hofer, B. K., \& Pintrich, P. R. (Eds.). (2002). Personal epistemology: The psychology of beliefs about knowledge and knowing. Erlbaum. 
Irzik, G., \& Nola, R. (2014). New directions for nature of science research. In M. Matthews (Ed.), International handbook of research in history, philosophy and science teaching (pp. 999-1021). Springer.

Knorr-Cetina, K. (1999). Epistemic cultures: How the sciences make knowledge. Harvard University Press.

Lederman, N. G. (1992). Students' and teachers' conceptions of the nature of science: A review of the research. Journal of Research in Science Teaching, 29(4), 331-359. https://doi.org/10.1002/tea. 3660290404

Lederman, N. G., Abd-El-Khalick, F., Bell, R. L., \& Schwartz, R. S. (2002). Views of nature of science questionnaire: Towards valid and meaningful assessment of learners' conceptions of the nature of science. Journal of Research in Science Teaching, 39(6), 497-521. https://doi.org/10.1002/tea. 10034

Leung, J. S. C. (2020). A practice-based approach to learning nature of science through socioscientific issues. Research in Science Education. https://doi.org/10.1007/s11165-020-09942-w

McDonald, C. (2017). Exploring representations of nature of science in Australian junior secondary school science textbooks: A case study of genetics. In C. McDonald \& F. Abd-El-Khalick (Eds.), Representations of nature of science in school science textbooks: A global perspective (pp. 98-117). Routledge.

Milne, C., \& Taylor, P. C. (1995). Metaphors as global markers for teachers' beliefs about the nature of science. Research in Science Education, 25, 39-49. https://doi.org/10.1007/BF02356459

Nouri, N., \& McComas, W. F. (2021). History of science (HOS) as a vehicle to communicate aspects of nature of science (NOS): Multiple cases of HOS instructors' perspectives regarding NOS. Research in Science Education, 51, 289-305. https://doi.org/10.1007/s11165-019-09879-9

Osborne, J., Collins, S., Ratcliffe, M., Millar, R., \& Duschl, R. (2003). What ideas-about-science should be taught in school science? A Delphi study of the expert community. Journal of Research in Science Teaching, 40(7), 692-720. https://doi.org/10.1002/tea.10105

Park, W., Yang, S., \& Song, J. (2020). Eliciting students' understanding of nature of science with textbased tasks: Insights from new Korean high school textbooks. International Journal of Science Education, 42(3), 426-450. https://doi.org/10.1080/09500693.2020.1714094

Park, W., Wu, J., \& Erduran, S. (2020). The nature of STEM disciplines in the science education standards documents from the United States, Korea and Taiwan: Focusing on disciplinary aims, values and practices, Science \& Education. Science \& Education 29(4), 899-927.

Peters-Burton, E. E. (2015). Outcomes of a self-regulatory curriculum model: Network analysis of middle school students' views of nature of science. Science \& Education, 24, 855-885. https://doi.org/ 10.1007/s11191-015-9769-3

Peters-Burton, E. E., \& Baynard, E. (2013). Network analysis of domains of knowledge about the scientific enterprise: A comparison of scientists, middle school science teachers and 8th grade science students. International Journal of Science Education, 35, 2801-2837. https://doi.org/10.1080/09500 693.2012.662609

Peters-Burton, E. E., Parrish, J. C., \& Mulvey, B. K. (2019). Extending the utility of the Views of Nature of Science assessment through epistemic network analysis. Science \& Education, 28(9), 1027-1053.

Petersen, I., Herzog, S., Bath, C., \& Fleißner, A. (2020). Contextualisation of factual knowledge in genetics: A pre- and post-survey of undergraduates' understanding of the nature of science. Interdisciplinary Journal of Environmental and Science Education, 16(2), e22115. https://doi.org/10.29333/ ijese/7816.

Romero-Maltrana, D., \& Duarte, S. (2020). A new way to explore the nature of science: Meta-categories rather than lists. Research in Science Education. https://doi.org/10.1007/s11165-020-09940-y

Schwartz, R., \& Lederman, N. G. (2008). What scientists say: Scientists' views of nature of science and relation to science context. International Journal of Science Education, 30(6), 727-771. https://doi. org/10.1080/09500690701225801

Scott, J. (1988). Social network analysis. Sociology, 22(1), 109-127. https://doi.org/10.1177/0038038588 022001007

Shaffer, D., Hatfield, D., Svarovsky, G., Nash, P., Nulty, A., Bagley, E., Frank, K., Rupp, A., \& Mislevy, M. (2009). Epistemic network analysis: A prototype for 21 st-century assessment of learning. International Journal of Learning and Media, 1, 33-53.

Shaffer, D., Collier, W., \& Ruis, A. (2016). A tutorial on epistemic network analysis: Analyzing the structure of connections in cognitive, social, and interaction data. Journal of Learning Analytics, 3, 9-45. 
Strauss, A., \& Corbin, J. (1998). Basics of qualitative research: Techniques and procedures for developing grounded theory. Sage.

Tao, P. K. (2002). A study of students' focal awareness when studying science stories designed for fostering understanding of the nature of science. Research in Science Education, 32, 97-120. https://doi. org/10.1023/A:1015010221353

Teddlie, C., \& Tashakkori, A. (2009). Foundations of mixed methods research: Integrating quantitative and qualitative approaches in the social and behavior sciences. Sage.

Wong, S. L., \& Hodson, D. (2009). From the horse's mouth: What scientists say about scientific investigation and scientific knowledge. Science Education, 93(1), 109-130. https://doi.org/10.1002/sce. 20290

Wu, J. Y., \& Erduran, S. (2022). Investigating scientists' views about the utility of the family resemblance approach to nature of science in science education. Science \& Education. https://doi.org/10.1007/ s11191-021-00313-Z

Zion, M., Schwartz, R. S., Rimerman-Shmueli, E., \& Adler, I. (2002). Supporting teachers' understanding of nature of science and inquiry through personal experience and perception of inquiry as a dynamic process. Research in Science Education, 50, 1281-1304. https://doi.org/10.1007/ s11165-018-9732-9 